\title{
TIM-3 expression and its association with overall survival in primary osteosarcoma
}

\author{
FEIFEI PU ${ }^{1}$, FENGXIA CHEN ${ }^{3,4}$, ZHICAI ZHANG ${ }^{1}$, XIANGCHENG QING $^{1}$, \\ HUI LIN ${ }^{1}$, LEI ZHAO ${ }^{1}$, PING XIA ${ }^{2}$ and ZENGWU SHAO ${ }^{1}$ \\ ${ }^{1}$ Department of Orthopedics, Union Hospital, Tongji Medical College, Huazhong University of Science and Technology, \\ Wuhan, Hubei 430022; ${ }^{2}$ Department of Orthopedics, Wuhan Integrated Traditional Chinese Medicine and \\ Western Medicine Hospital; ${ }^{3}$ Department of Radiation and Medical Oncology; ${ }^{4}$ Hubei Cancer Clinical Study Centre, \\ Zhongnan Hospital of Wuhan University, Wuhan, Hubei 430071, P.R. China
}

Received June 3, 2018; Accepted April 15, 2019

DOI: $10.3892 / \mathrm{ol} .2019 .10855$

\begin{abstract}
T-cell immunoglobulin and mucin domaincontaining-3 (TIM-3) performs a critical function in immune tolerance by suppressing the activation and proliferation of T cells. TIM-3 serves an important role in tumor progression in a number of carcinomas, including non-small cell lung cancer, hepatitis B virus-associated hepatocellular carcinoma, Langerhans cell sarcoma, head and neck cancer and follicular B cell non-Hodgkin lymphoma. The aim of the present study was to evaluate the possible association of TIM-3 with the prognosis of osteosarcoma. TIM-3 expression was assessed by immunohistochemical analysis in osteosarcoma tissues. The association between TIM-3 expression and prognosis was examined. To assess the association between TIM-3 expression levels and clinicopathological features, a Fisher's exact test was used. TIM-3 overexpression was indicated to be associated with surgical treatment and survival. Kaplan-Meier analysis indicated that TIM-3 is an independent predictor of overall survival, and its overexpression was indicated to be associated with poor prognosis in patients with osteosarcoma. Additionally, reverse transcription-quantitative polymerase chain reaction and western blot analysis were carried out to evaluate TIM-3 expression levels in fresh tumor tissue samples, adjacent-tissue samples, osteosarcoma cell lines, and in an osteoblastic cell line. TIM-3 was indicated to be overexpressed in fresh osteosarcoma tissue samples and in osteosarcoma cell lines. In conclusion, TIM-3 overexpression is associated with poor survival among patients with osteosarcoma and may be a possible therapeutic target in these types of tumors.
\end{abstract}

Correspondence to: Professor Zengwu Shao, Department of Orthopedics, Union Hospital, Tongji Medical College, Huazhong University of Science and Technology, 1277 Jiefang Avenue, Wuhan, Hubei 430022, P.R. China

E-mail: szwjj@medmail.com.cn

Key words: T-cell immunoglobulin and mucin domain-containing 3, osteosarcoma, prognosis

\section{Introduction}

Osteosarcoma is an osteoblastoma of mesenchymal origin. It is the most common primary malignant tumor of the bone and tends to occur in teenagers (1). Although primary bone cancers account for only $0.2 \%$ of all malignant tumors, the results are severe in children and adults once they develop this cancer (1). According to the National Cancer Institute Surveillance, Epidemiology, and End Results program, cancer prevalence increased at an annual rate of $\sim 0.3 \%$ over the previous decade (2). Although osteosarcoma usually occurs at the age between 5 and early adulthood, in recent years, the incidence rate among elderly patients has increased, and $\sim 60 \%$ of osteosarcomas occur in patients $<20$ years old, and $\sim 10 \%$ of patients are $>60$ years old (3). It has been reported that the emergence of this phenomenon may be highly associated with a history of Paget's disease and radiotherapy (4).

In the last decade, immunotherapy has been considered as one of the most promising potential means of treatments for patients with various types of cancer (5-8). The emergence of immunotherapy for tumor treatment provides novel insight, as this modality has been reported to activate the body's immune system, enhance an antitumor immune response, kill vulnerable tumor cells, and inhibit tumor proliferation and metastasis. The reported results of immunotherapy are promising, and clinical applications have indicated that immunotherapy is effective, where a number of patients with cancer even achieve long-term recovery (5). The immune system recognizes novel tumor antigens usually as foreign substances, therefore, eliminating tumors via an immune response (6). When the body recognizes the novel tumor antigen, the immune response starts (7). In this process, interactions between different immune cells are critical for tumor elimination. Nevertheless, a number of tumors, such as renal cell carcinoma, pancreatic cancer, glioma and colorectal cancer, secrete proteins called immunocheckpoint inhibitors via tumor-specific immune cells (7). This combination activates an inhibitory pathway that limits normal immune responses, thereby allowing tumors to evade or suppress immune responses (5-7). The most recent immunotherapeutic approaches target these mechanisms of immune tolerance by blocking immune checkpoints to revive 
a functionally suppressed immune response, reinvigorate T cells, and promote antitumor immunity (9).

T-cell immunoglobulin and mucin domain-containing-3 (TIM-3), also known as HAVCR2, has been recognized as a member of the TIM gene family, which includes TIM-1, TIM-3, and TIM-4 in humans and Tim-1 through Tim- 8 in mice (10). TIM-3 is expressed on T helper 1 (Th1), Th17, and $\mathrm{CD}^{+} \mathrm{T}$ cells (cells of myeloid lineages) (11). Engagement of its ligands by TIM-3 has been indicated to suppress Th1 and Th17 responses and to induce peripheral immune tolerance, supporting an inhibitory role of TIM-3 in T-cell-mediated immune responses (12). The expression levels of programmed cell death 1 (PD-1) and TIM-3 in tumor tissues are significantly associated with PD1 and TIM-3 polymorphisms, and administration of TIM-3 and PD-1 synergistically promotes tumor growth (13). The aforementioned preclinical studies indicate an inhibitory effect of TIM-3 on antitumor immunity.

However, the association between TIM-3 and osteosarcoma, to the best of our knowledge, remains unclear. Therefore, the aim of the present study was to analyze the expression level of TIM-3 in primary osteosarcoma and its possible association with survival of patients with osteosarcoma.

\section{Materials and methods}

Acquisition of human tissue samples. The present study was approved by The Ethics Committee of Union Hospital Tongji Medical College of Huazhong University of Science and Technology (Wuhan, China) and conforms to the provisions of the Declaration of Helsinki. Tissue collection process was approved by the Ethics Committee, all patients and legal guardians provided written informed consent regarding human tissue acquisition used in the present study, in accordance with National Regulations on the Use of Clinical Samples in China. A total of 38 pairs of osteosarcoma tissue samples were obtained from patients with osteosarcoma, who underwent surgical resection at the Union Hospital between January 2011 and June 2016, and eight groups of fresh tissue samples, including tumor and adjacent tissues were obtained between January and November in 2016. Among the 38 patients, 26 were male and 12 were female, ranging in age from 8-72 years old, and the median age was 18 years old. The eight fresh specimens included five male and three females, aged from 12-46 years, with a median age of 14 years. Patients receiving chemotherapy or radiotherapy prior to surgical treatment were excluded from the study. The diagnosis and Enneking stage of osteosarcoma was assessed by two experienced pathologists independently, (Union Hospital, Tongji Medical College, Huazhong University of Science and Technology, Wuhan, China) in a blinded manner, and according to the Enneking system and the 2015 World Health Organization Classification of Tumors $(14,15)$. All patients and legal guardians provided written informed consent regarding human tissue acquisition used in the present study, in accordance with National Regulations on the Use of Clinical Samples in China.

Cell culture. Human osteosarcoma cell lines U-2OS, MG63, and SAOS and osteoblastic cell line hFOB1.19 were purchased from the Type Culture Collection of the Chinese Academy of Sciences. The U-2OS, MG63, and SAOS cells were cultured in
Eagle's minimum essential medium (ATCC) supplemented with 10\% FBS (Thermo Fisher Scientific, Inc.). hFOB1.19 cells were cultured in McCoy's 5a modified medium (ATCC) containing $10 \% \mathrm{FBS}$. All cells were cultured at $37^{\circ} \mathrm{C}$ with $5 \% \mathrm{CO}_{2}$.

Immunohistochemical (IHC) staining. Staining was performed on $4 \mu \mathrm{m}$ tissue microarray sections of formalin-fixed in $10 \%$ formalin at $4^{\circ} \mathrm{C}$ for $24 \mathrm{~h}$ and subsequently paraffin-embedded. The slices were deparaffinized in xylene and dehydrated in a graded series of ethanol solutions, deparaffinized and hydrated in $100 \%$ alcohol for $5 \mathrm{~min}$ followed by $80 \%$ alcohol for $5 \mathrm{~min}$. The endogenous peroxidase activity was quenched with $0.3 \%$ hydrogen peroxide. Antigen retrieval was performed with citrate buffer at $98^{\circ} \mathrm{C}$ for $10 \mathrm{~min}$ and endogenous peroxidase activity was blocked using $0.3 \%$ hydrogen peroxide in methanol for $15 \mathrm{~min}$ at room temperature. Antigen retrieval was performed in $0.01 \mathrm{~mol} / 1$ citric acid buffer and non-specific binding was blocked with $10 \%$ normal goat serum (Wuhan Servicebio Technology Co., Ltd., Wuhan, China) at $37^{\circ} \mathrm{C}$ for $30 \mathrm{~min}$. Subsequently, overnight incubation at $4^{\circ} \mathrm{C}$ was carried out with an anti-human TIM-3 monoclonal antibody (dilution, 1:100; R\&D Systems, Inc., Minneapolis, MN, USA), followed by a $30 \mathrm{~min}$ incubation at $37^{\circ} \mathrm{C}$ with a horseradish peroxidase-labeled anti-rabbit IgG antibody (dilution, 1:500; R\&D Systems, Inc.). Samples were incubated with the primary antibodies overnight at $4^{\circ} \mathrm{C}$. Subsequently, the samples were incubated with horseradish peroxidase universal immunoglobulin $\mathrm{G}(\mathrm{IgG})$ secondary antibody (cat. no. sc69786; 1:1,000; Santa Cruz Biotechnology, Inc., Dallas, TX, USA) for $30 \mathrm{~min}$ at $37^{\circ} \mathrm{C}$. A histostaining kit (cat. no. SP9001; OriGene Technologies, Inc., Beijing, China) was used to visualize antibody binding on the slides, according to the manufacturer's protocol. The tissue slices were incubated with DAB (Wuhan Servicebio Technology Co., Ltd., Wuhan, China) and lightly counterstained with $0.5 \%$ hematoxylin for $5 \mathrm{~min}$ at $37^{\circ} \mathrm{C}$. Slides which had not been treated with a primary antibody were used as the negative control and the breast cancer tissues slides which had previously been confirmed to overexpress the TIM-3 protein were used as the positive controls. The slides were observed using a light microscope at x200 magnification (IX71; Olympus, Tokyo, Japan).

Tim-3 immunoreactivity was assessed independently by two pathologists blinded to the origin of the tissue with the use of a labeling index. A total of 100 cells were counted in 3 random fields and the percentage of positive cells were calculated. The extent of staining, calculated as the percentage of stained cells, and the intensity of immunostaining were taken into consideration in the analysis of data. The semi-quantitative immunoreaction scoring system was evaluated based on the percentage of positive cells added to the stain intensity. Regarding stain intensity, negative staining was defined as 0 , weakly positive was defined as 1 , moderately positive as 2 and strongly positive as 3 . The scores of immuno-positive cells were defined as follows: $<5 \%$ Positive cells was defined as 0 (negative); 5-25\% immuno-positive cells as 1 (low); $25-75 \%$ immuno-positive cells as 2 (moderate); and $>75 \%$ immuno-positive cells as 3 (high). The sum of the stain intensity and positive cell scores was the final score given to each section and defined as:,$- 0 ;+, 1$ or $2 ;++, 3$ or 4 ; and,+++ 5 or 6 . The intensity of staining was scored between 0 and 3 , and the extent of staining was scored between 0 and $100 \%$. The final quantitation of IHC staining in each sample was obtained by 
multiplying the two scores. TIM-3 expression was classified as high if the score was $>1.1$ (median score), while a score of $\leq 1.1$ was classified as low expression of TIM-3.

Reverse transcription-quantitative polymerase chain reaction $(R T-q P C R)$. TRIzol ${ }^{\circledR}$ was used to extract total RNA from the patients' frozen tissues and the osteosarcoma cell lines, including U2OS, MG-63 and SAOS, and the osteoblast cell line, hFOB1.19. Analysis of relative gene expression data from RT-qPCR was performed using the $2^{-\Delta \Delta \mathrm{Cq}}$ method (16). Total RNA $(1 \mu \mathrm{g})$ was reverse-transcribed into cDNA in a total volume of $20 \mu \mathrm{l}$ using the RT Reaction kit (Promega Corporation, Madison, WI, USA), according to the manufacturer's protocols. RT-qPCR was conducted with the Express SYBR-GreenER qPCR Supermix Universal kit (Invitrogen; Thermo Fisher Scientific, Inc., Waltham, MA, USA), according to the manufacturer's protocols, on a Rotor-gene 6000 system (Qiagen China Co., Ltd., Shanghai, China). A total of $25 \mu \mathrm{l}$ PCR mixture contained $2 \mu 1$ the reverse-transcribed product, $12.5 \mu 1$ SYBR-Green Supermix, $8.5 \mu \mathrm{l}$ RNase-free water, and $1 \mu \mathrm{l}$ each of forward and reverse primers. The reaction was run in a 72-well optical plate in triplicate. The first step of the thermal-cycling program was initial denaturation at $95^{\circ} \mathrm{C}$ for $10 \mathrm{sec}$, followed by 40 cycles of $95^{\circ} \mathrm{C}$ for $5 \mathrm{sec}$ and $60^{\circ} \mathrm{C}$ for $30 \mathrm{sec}$ as the second step. A melting-curve analysis was performed to ensure specificity of the PCR products. The following primers were employed: H-TIM-3 forward, 5'-GTGACTCTAGCAGACAGTGGGAT-3' and reverse, 5'-TGACCTTGGCTGGTTTGATG-3', and $\beta$-actin forward, 5'-CACCCAGCACAATGAAGATCAAGAT-3' and reverse, (5'-CCAGTTTTTAAATCCTGAGTCAAGC-3'). $\beta$-actin was used as the internal control.

Western blot analysis. The osteosarcoma cell lines and osteoblast cell line $\left(2 \times 10^{6}\right.$ cells $\left./ \mathrm{ml}\right)$ were harvested and washed three times with cold PBS. Cells were lysed in ice-cold lysis buffer (50 mM Tris-HCl, pH 7.4, $250 \mathrm{mM} \mathrm{NaCl}, 50 \mathrm{mM} \mathrm{NaF}, 5 \mathrm{mM}$ EDTA, $0.1 \%$ Triton $\mathrm{X}-100$ and $0.1 \mathrm{mM} \mathrm{Na}_{3} \mathrm{VO}_{4}$ ). Following centrifugation at $12,000 \times \mathrm{g}$ for $15 \mathrm{~min}$ at $4^{\circ} \mathrm{C}$ to remove all organelles, the supernatants were removed, and the protein levels were estimated using a Super-Bradford Protein assay kit (CoWin Biosciences Co., Ltd., Beijing, China), according to the manufacturer's protocol. Equal amounts of proteins (20 $\mu \mathrm{g} /$ lane) were denatured in SDS-PAGE buffer, resolved by SDS-PAGE on a $12 \%$ Tris-glycine gel and transferred onto PVDF membranes. Membranes were blocked with 5\% skimmed milk in TBS containing $0.1 \%$ Tween-20 (TBST) for $1 \mathrm{~h}$ at room temperature. After washing with TBST three times, membranes were incubated with a primary antibody against TIM-3 (1:100; cat. no. 1315; Sigma-Aldrich; Merck KGaA; Darmstadt, Germany) or $\beta$-actin (cat. no. abs20002; Absin Bioscience Co., Ltd. Shanghai, China) overnight at $4^{\circ} \mathrm{C}$ in TBST. After incubation with horseradish peroxidase-conjugated goat anti-rabbit IgG (1:10,000; cat. no. BA1055; Boster Biological Technology) in TBST at room temperature for $60 \mathrm{~min}$, bands were detected using enhanced chemiluminescence detection system (APG Bio Ltd., Shanghai, China). ImageJ version 1.0 (National Institutes of Health, Bethesda, MD, USA) was used for quantitative analysis of the bands. To account for any differences in loading, target band densitometries were divided by the density of $\beta$-actin obtained from the same lane.
Table I. The clinical characteristics of the 38 patients with osteosarcoma.

\begin{tabular}{lrc}
\hline Clinical characteristics & Cases & Percent $(\%)$ \\
\hline Age (years) & & \\
$>40$ & 12 & 31.58 \\
$20-40$ & 5 & 13.16 \\
$<20$ & 21 & 55.26 \\
Sex & & \\
Male & 26 & 68.42 \\
Female & 12 & 31.58 \\
WHO Pathological classification & & \\
Conventional osteosarcoma & 27 & 71.05 \\
Telangiectatic osteosarcoma & 3 & 7.89 \\
Parosteal osteosarcoma & 2 & 5.26 \\
Small round cell osteosarcoma & 2 & 5.26 \\
Fibrous tissue osteosarcoma & 1 & 2.63 \\
Other & & \\
Tumor location & 3 & 7.89 \\
Femur & 20 & 52.63 \\
Shin & 11 & 28.95 \\
Other & 7 & 18.42 \\
Enneking & & \\
IIB & 19 & 50.00 \\
III & 19 & 50.00 \\
Surgical & & \\
Salvage & 11 & 28.95 \\
Amputation & 27 & 71.05 \\
Overall survival time & & \\
Yes & 16 & 42.11 \\
No & 22 & 57.89 \\
\hline
\end{tabular}

TIM-3, T-cell immunoglobulin and mucin domain-containing-3; Enneking, Enneking-Musculoskeletal Tumor Staging system; WHO, world health organization.

Statistical analysis. The SPSS 20.0 software (IBM Corp., Armonk, NY, USA) was used to analyze the data. Data are presented as the mean \pm standard deviation and categorical data were tested using a t-test or a Wilcoxon signed-rank test. All the tests in the present study were two-sided. The expression of TIM- 3 and the clinical and pathological factors were analyzed using a $\chi^{2}$ test or a Fisher's exact test. Spearman's correlation analysis was performed to investigate the correlation between TIM-3 mRNA and protein expression levels. Overall survival time was defined as the time from cancer diagnosis until the patient succumbed to the disease. Survival was assessed by the Kaplan-Meier method, and differences between curves were estimated by the log-rank test. $\mathrm{P}<0.05$ was considered to indicate a statistically significant difference.

\section{Results}

Baseline characteristics of patients. The clinical characteristics of the 38 patients with osteosarcoma are detailed in Table I. TIM-3 expression levels were evaluated by tissue type, 
Table II. Association between TIM-3 expression and clinicopathological parameters.

\begin{tabular}{|c|c|c|c|c|}
\hline \multirow[b]{2}{*}{ Classification } & \multicolumn{4}{|c|}{$\begin{array}{l}\text { Immunohistochemical } \\
\text { staining score }\end{array}$} \\
\hline & - & + & ++ & +++ \\
\hline \multicolumn{5}{|l|}{ Tissue types } \\
\hline Adjacent tissues & 7 & 9 & 2 & 1 \\
\hline Tumor tissues & 2 & 6 & 6 & 24 \\
\hline \multicolumn{5}{|l|}{ Sex } \\
\hline Male & 2 & 1 & 5 & 12 \\
\hline Female & 3 & 2 & 4 & 9 \\
\hline \multicolumn{5}{|l|}{ Age (years) } \\
\hline$>40$ & 2 & 1 & 4 & 8 \\
\hline $20-40$ & 0 & 2 & 4 & 6 \\
\hline$<20$ & 1 & 2 & 7 & 9 \\
\hline \multicolumn{5}{|l|}{ WHO Pathological classification } \\
\hline Conventional osteosarcoma & 2 & 3 & 8 & 14 \\
\hline Telangiectatic osteosarcoma & 0 & 0 & 1 & 2 \\
\hline Parosteal osteosarcoma & 0 & 1 & 0 & 1 \\
\hline Small round cell osteosarcoma & 0 & 0 & 1 & 1 \\
\hline Fibrous tissue osteosarcoma & 0 & 1 & 0 & 0 \\
\hline Other & 0 & 1 & 2 & 0 \\
\hline \multicolumn{5}{|l|}{ Enneking } \\
\hline IIB & 2 & 5 & 8 & 4 \\
\hline III & 1 & 2 & 5 & 11 \\
\hline \multicolumn{5}{|l|}{ Surgical type } \\
\hline Salvage & 3 & 5 & 2 & 1 \\
\hline Amputation & 2 & 4 & 9 & 12 \\
\hline \multicolumn{5}{|l|}{ Overall survival time } \\
\hline Yes & 4 & 8 & 3 & 1 \\
\hline No & 1 & 2 & 4 & 15 \\
\hline
\end{tabular}

TIM-3, T-cell immunoglobulin and mucin domain-containing 3; Enneking, Enneking-Musculoskeletal Tumor Staging System; WHO, world health organization.

sex, age, pathological type, Enneking stage, surgical status, and survival (Table II). Table III presents the association between TIM-3 expression and prognosis of the patients with osteosarcoma. Significant associations were observed between TIM-3 expression and the type of tissue $(\mathrm{P}<0.001)$, surgical status $(\mathrm{P}=0.008)$, and survival $(\mathrm{P}<0.001)$, among the patients with osteosarcoma; however, no significant associations between TIM-3 with the other parameters, such as sex, age, Enneking stage and pathological classification were detected (Table III).

Detection of TIM-3 mRNA and protein expressions in osteosarcoma tissues and cell lines. RT-qPCR and western blot analysis were conducted to assess TIM-3 expression levels in fresh tumor tissue samples and adjacent-tissue samples. TIM-3 was indicated to have an increased expression in tumor tissue samples (P<0.001; Fig. 1). Subsequently, RT-qPCR and western blot analysis were carried out to analyze the TIM-3 expression
Table III. Association between TIM-3 expression and prognosis in patients with osteosarcoma.

\begin{tabular}{|c|c|c|c|}
\hline Variables & Negative & Positive & P-value \\
\hline Tissue types & & & $<0.001$ \\
\hline Adjacent tissues & 16 & 3 & \\
\hline Tumor tissues & 8 & 30 & \\
\hline Sex & & & 0.438 \\
\hline Male & 3 & 17 & \\
\hline Female & 5 & 13 & \\
\hline Age (years) & & & 1.000 \\
\hline$>40$ & 3 & 12 & \\
\hline $20-40$ & 2 & 10 & \\
\hline$<20$ & 3 & 16 & \\
\hline WHO Pathological classification & & & 0.278 \\
\hline Conventional osteosarcoma & 5 & 22 & \\
\hline Telangiectatic osteosarcoma & 0 & 3 & \\
\hline Parosteal osteosarcoma & 1 & 1 & \\
\hline Small round cell osteosarcoma & 0 & 2 & \\
\hline Fibrous tissue osteosarcoma & 1 & 0 & \\
\hline Other & 1 & 2 & \\
\hline Enneking & & & 0.269 \\
\hline IIB & 7 & 12 & \\
\hline III & 3 & 16 & \\
\hline Surgical type & & & 0.008 \\
\hline Salvage & 8 & 3 & \\
\hline Amputation & 6 & 21 & \\
\hline Overall survival time & & & $<0.001$ \\
\hline Yes & 12 & 4 & \\
\hline No & 3 & 19 & \\
\hline
\end{tabular}

TIM-3, T-cell immunoglobulin and mucin domain-containing 3; Enneking, Enneking-Musculoskeletal Tumor Staging System; WHO, world health organization.

levels in human osteosarcoma cell lines, U-2OS, MG63, and SAOS and in osteoblastic cell line hFOB1.19. TIM-3 indicated an increased expression level in U-2OS, MG63, and SAOS cells, however, not in hFOB1.19 cells ( $\mathrm{P}<0.001$; Fig. 2).

Immunohistochemistry of TIM-3 protein expression and survival analysis. The positive expression of TIM-3 was showed as brown-yellow granules and located in the cytoplasm and/or membrane of tumor cells. Among 38 osteosarcoma tumor tissues, 36 tumor tissues showed positive expression of TIM-3, with a positive expression rate of 94.74\%; among 19 adjacent-tissues, 12 specimens showed positive expression of TIM-3, with a positive expression rate of $63.16 \%(\mathrm{P}<0.001)$. The IHC staining score of TIM-3 expression in primary osteosarcoma tissue samples was notably higher compared with adjacent-tissue samples (Fig. 3). As presented in Fig. 4, the Kaplan-Meier analysis predicted that patients with high TIM-3 expression $(n=24)$ would have shorter overall survival compared with patients 

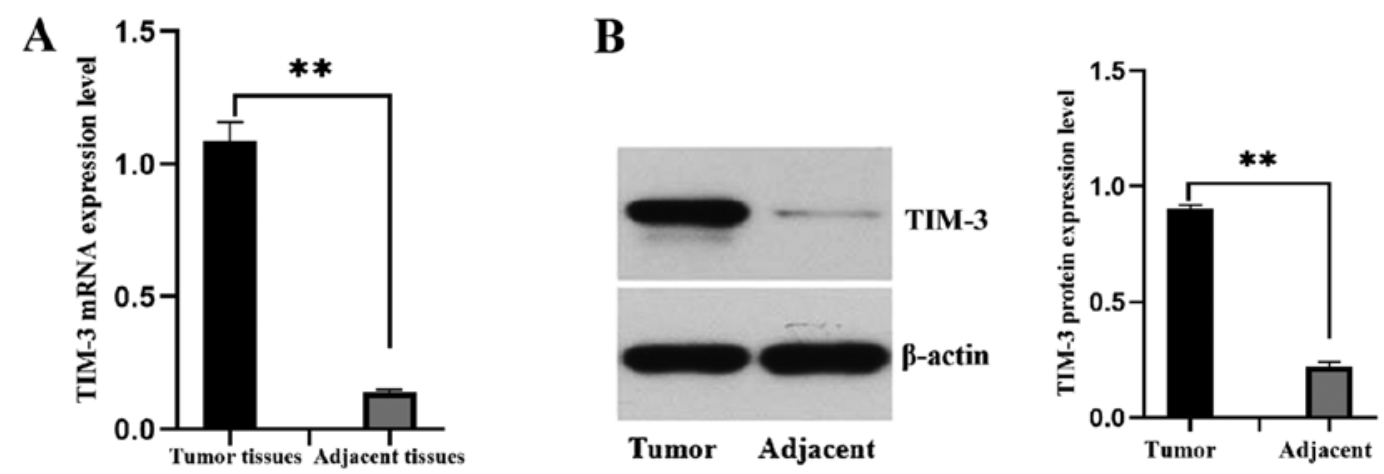

Figure 1. Detection of TIM-3 mRNA and protein expression levels in cancer tissue. (A) TIM-3 mRNA expression level in osteosarcoma tumor tissue samples and adjacent-tissue samples. TIM-3 mRNA indicated an increased expression in tumor tissues compared with adjacent. (B) Western blot analysis and quantification of results of the TIM-3 expression levels in tumor tissue samples and adjacent-tissue samples. TIM-3 indicated an increased expression in tumor tissue samples compared with adjacent-tissue samples. ${ }^{* *} \mathrm{P}<0.001$ vs. adjacent tissues. TIM-3, T-cell immunoglobulin and mucin domain-containing 3 .

A

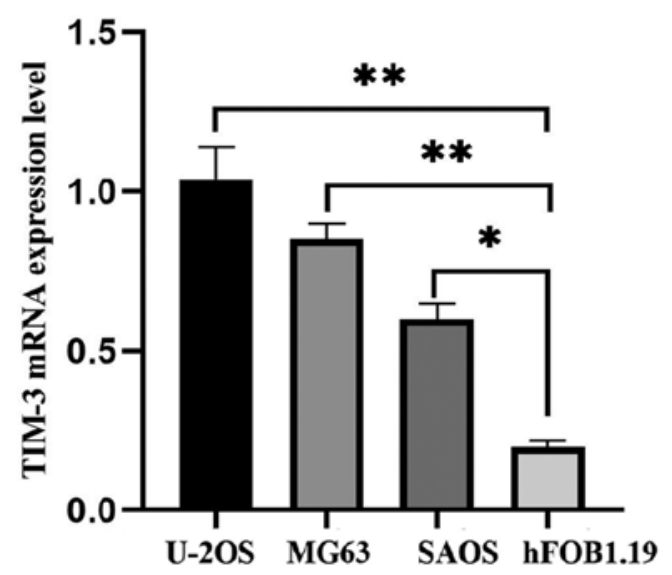

B

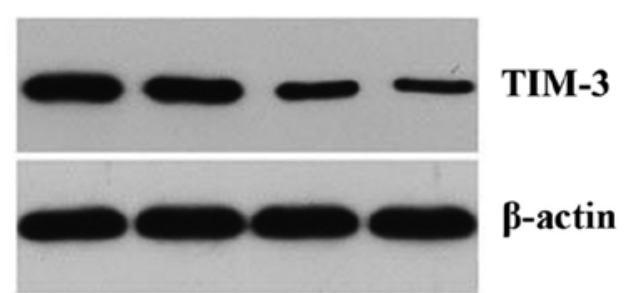

U-2OS MG63 SAOS hFOB1.19

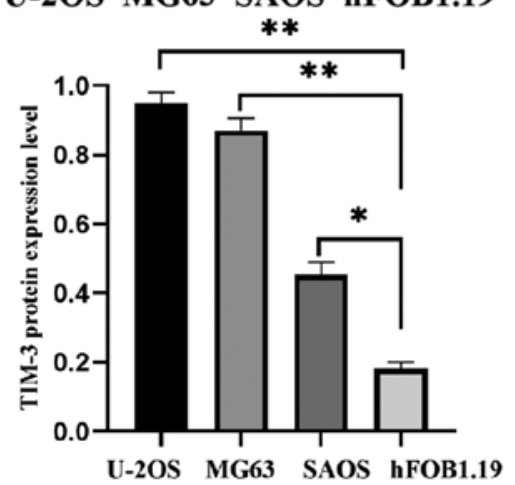

Figure 2. Detection of TIM-3 mRNA and protein expression levels in osteosarcoma and osteoblastic cell lines. (A) mRNA TIM-3 levels in human osteosarcoma cell lines U-2OS, MG63, and SAOS and in osteoblastic cell line hFOB1.19. (B) Western blot analysis and quantification of results of TIM-3 expression level in human osteosarcoma cell lines U-2OS, MG63, and SAOS and in osteoblastic cell line hFOB1.19. ${ }^{*} \mathrm{P}<0.05,{ }^{* * *} \mathrm{P}<0.01$ vs. hFOB1.19. TIM-3, T-cell immunoglobulin and mucin domain-containing-3.

with low TIM-3 expression $(\mathrm{n}=14)(\mathrm{P}<0.001)$. This result suggests that high TIM-3 expression is significantly associated with an increased risk of mortality.

\section{Discussion}

Osteosarcoma is a cancer originating from primitive mesenchymal cells and is the most common type of primary malignant bone tumor in children and adolescents (17). With advances in multimodal treatments consisting of adjuvant chemotherapy and surgical resection, the prognosis and quality of life of patients with non-metastatic osteosarcoma of the extremities have improved. However, the 5-year progression-free survival of patients with high-grade osteosarcoma is only $50 \%$, due to a poor response to chemotherapy (18). Therefore, it is necessary to devise novel therapeutic strategies for improving the overall rate of survival.
In a study by Shang et al (19), TIM-3 expression resulted in tumor cells acquiring features associated with aggressive epithelial-mesenchymal transition and thus may be involved in the pathogenesis of osteosarcoma (19). A recent study revealed that aberrant expression of the TIM-3 antigen on peripheral blood $\mathrm{T}$ cells is associated with progressive disease in patients with osteosarcoma, and TIM-3 may be a possible diagnostic biomarker of osteosarcoma and/or a prognostic biomarker of osteosarcoma progression (20).

In the present study, TIM-3 expression was assessed by IHC staining in osteosarcoma tissue samples. The association between TIM-3 expression and survival was examined. An increase in TIM-3 expression was indicated to be associated with surgical status and survival. Kaplan-Meier analysis indicated that TIM-3 is an independent predictor of overall survival, and that its overexpression is associated with poor survival among patients with osteosarcoma. Piao et al (21) 

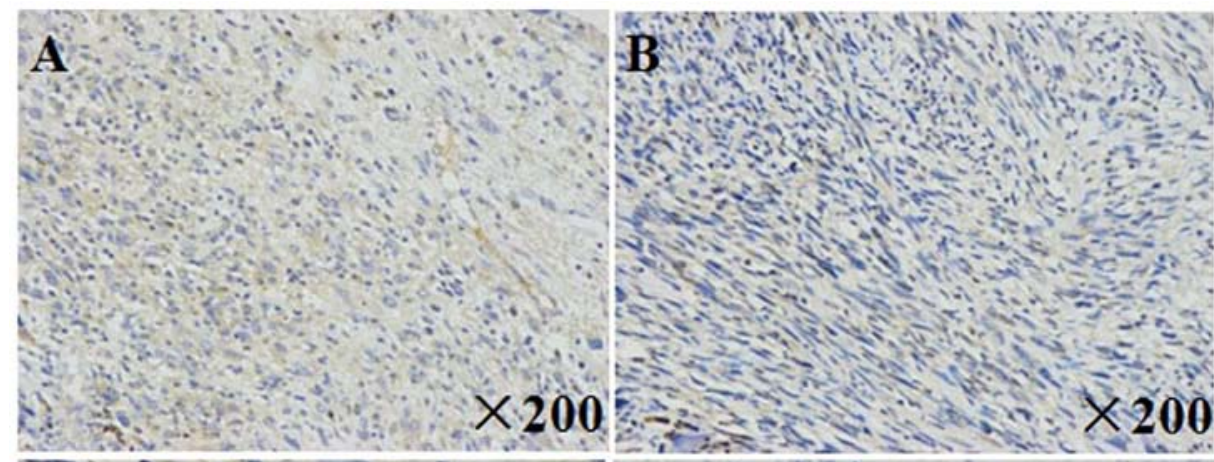

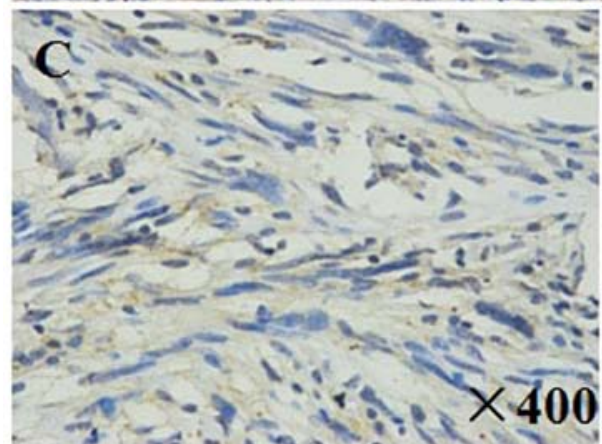

Tumor tissues

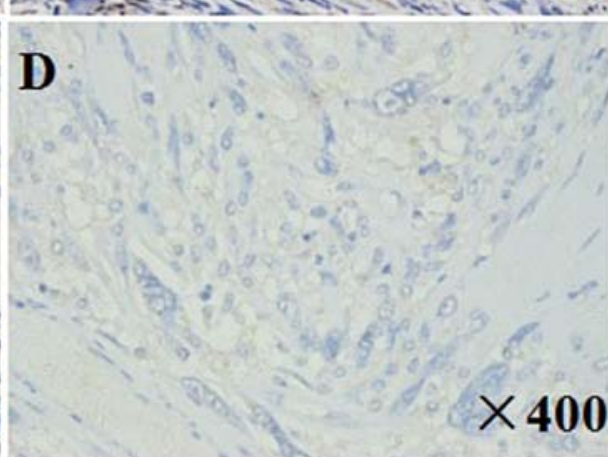

Adjacent tissues

Figure 3. Detection of TIM-3 protein expression levels using immunohistochemical staining. The immunohistochemical staining score of TIM-3 expression in primary osteosarcoma tissue samples is notably higher compared with the adjacent-tissue samples. (A) Representative image of expression of TIM-3 in the tumor tissues. Magnification, x200. (B) Representative image of expression of TIM-3 in the adjacent-tissue samples. Magnification, x200. (C) Representative image of expression of TIM-3 in the tumor tissues. Magnification, x400. (D) Representative image of expression of TIM-3 in the adjacent-tissue samples. Magnification, x400. TIM-3, T-cell immunoglobulin and mucin domain-containing-3.

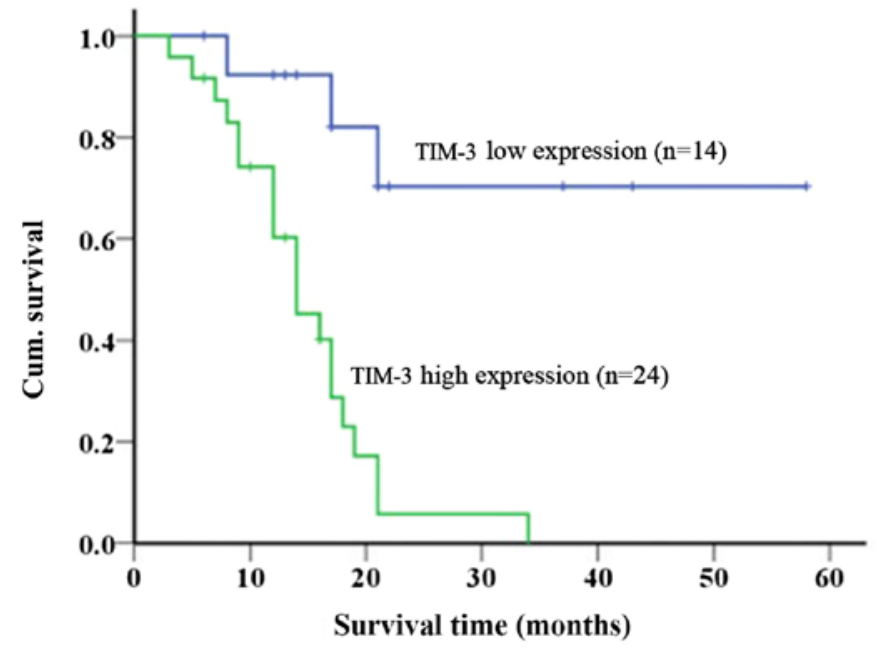

Figure 4. TIM-3 expression and Kaplan-Meier survival curves of patients with osteosarcoma. Kaplan-Meier analysis predicted that patients with osteosarcoma with high TIM-3 expression had shorter overall survival time compared with patients with low TIM-3 expression. P<0.001. TIM-3, T-cell immunoglobulin and mucin domain-containing-3; Cum., cumulative.

reported positive staining for TIM- 3 in prostate cancer tissues by IHC analysis, however, little or no staining for TIM-3 has been observed in an epithelium containing benign prostate hyperplasia (21). TIM-3 may affect the development and progression of prostate cancer, as this result may assist in the future use TIM-3 as a novel therapeutic target for effective prostate cancer management (21). Additionally, RT-qPCR and western blot analysis were conducted in the present study to evaluate TIM-3 expression levels in fresh tumor tissue samples, adjacent-tissue samples, osteosarcoma cell lines, and in an osteoblastic cell line. TIM-3 was increasing expressed in fresh tumor tissue samples and osteosarcoma cells. Nonetheless, further studies are required, in order to clarify the underlying biology of TIM-3 in the development of osteosarcoma.

In conclusion, the results of the present study revealed that high TIM-3 expression is significantly associated with poor survival and may be an independent predictor of survival among patients with osteosarcoma. TIM-3 expression was indicated to be a valuable prognostic biomarker of osteosarcoma.

\section{Acknowledgements}

Not applicable.

\section{Funding}

The present study was supported by National Natural Science Foundation of China (grant no. 81904231), the Scientific Research Program of Wuhan Health and Family Planning (grant no. WX17Q38 and WZ18Q05) and the Research Program of Wuhan No. 1 Hospital, Wuhan Integrated TCM and Western Medicine Hospital (grant no. 2017Y01).

\section{Availability of data and materials}

The datasets used and/or analyzed during the present study are available from the corresponding author on reasonable request. 


\section{Authors' contributions}

FP, FC, ZZ and XQ performed the experiments and wrote the manuscript. PX and ZS made substantial contributions to conception and design of the manuscript. PX and ZWS were responsible for the design of the experiments. HL and $\mathrm{LZ}$ analyzed the experimental data. HL, LZ, ZZ and XQ assisted with the statistical analysis. ZZ and XQ critically revised the manuscript and provided final approval of the version to be published and also made substantial contributions to conception and design. All authors read and approved the final manuscript.

\section{Ethics approval and consent to participate}

The present study was approved by The Ethics Committee of Union Hospital Tongji Medical College of Huazhong University of Science and Technology (Wuhan, China) and conforms to the provisions of the Declaration of Helsinki. All patients and legal guardians provided written informed consent regarding human tissue acquisition used in the present study, in accordance with National Regulations on the Use of Clinical Samples in China.

\section{Patient consent for publication}

Not applicable.

\section{Competing interests}

The authors declare that they have no competing interests.

\section{References}

1. Biermann JS, Adkins DR, Agulnik M, Benjamin RS, Brigman B Butrynski JE, Cheong D, Chow W, Curry WT, Frassica DA, et al: Bone cancer. J Natl Compr Canc Netw 11: 688-723, 2013.

2. Lindsey BA, Markel JE and Kleinerman ES: Osteosarcoma overview. Rheumatol Ther 4: 25-43, 2017.

3. He JP, Hao Y, Wang XL, Yang XJ, Shao JF, Guo FJ and Feng JX: Review of the molecular pathogenesis of osteosarcoma. Asian Pac J Cancer Prev 15: 5967-5976, 2014.

4. Mirabello L, Troisi RJ and Savage SA: Osteosarcoma incidence and survival rates from 1973 to 2004: Data from the Surveillance, Epidemiology, and End Results Program. Cancer 115: 1531-1543, 2009.

5. Liu S, Geng P, Cai X and Wang J: Comprehensive evaluation of the cytotoxic T-lymphocyte antigen- 4 gene polymorphisms in risk of bone sarcoma. Genet Test Mol Biomarkers 18: 574-579, 2014.
6. Fan Y, Zhang C, Jin S, Gao Z, Cao J, Wang A, Li D, Wang Q, Sun $X$ and Bai D: Progress of immune checkpoint therapy in the clinic (Review). Oncol Rep 41: 3-14, 2019.

7. Wang SD, Li HY, Li BH, Xie T, Zhu T, Sun LL, Ren HY and Ye ZM: The role of CTLA-4 and PD-1 in anti-tumor immune response and their potential efficacy against osteosarcoma. Int Immunopharmacol 38: 81-89, 2016.

8. Ledford H, Else H and Warren M: Cancer immunologists scoop medicine Nobel prize. Nature 562: 20-21, 2018.

9. Gibney GT, Weiner LM and Atkins MB: Predictive biomarkers for checkpoint inhibitor-based immunotherapy. Lancet Oncol 17: e542-e551, 2016

10. Markwick LJ, Riva A, Ryan JM, Cooksley H, Palma E, Tranah TH, Manakkat Vijay GK, Vergis N, Thursz M, Evans A, et al: Blockade of PD1 and TIM3 restores innate and adaptive immunity in patients with acute alcoholic hepatitis. Gastroenterology 148: 590-602.e10, 2015.

11. Das M, Zhu C and Kuchroo VK: Tim-3 and its role in regulating anti-tumor immunity. Immunol Rev 276: 97-111, 2017.

12. Sakuishi K, Ngiow SF, Sullivan JM, Teng MW, Kuchroo VK, Smyth MJ and Anderson AC: $\mathrm{TIM}^{+}{ }^{+} \mathrm{FOXP} 3^{+}$regulatory T cells are tissue-specific promoters of T-cell dysfunction in cancer. Oncoimmunology 2: e23849, 2013.

13. Li Z, Li N, Li F, Zhou Z, Sang J, Chen Y, Han Q, Lv Y and Liu Z: Immune checkpoint proteins PD-1 and TIM-3 are both highly expressed in liver tissues and correlate with their gene polymorphisms in patients with HBV-related hepatocellular carcinoma. Medicine (Baltimore) 95: e5749, 2016.

14. Present D, Bertoni F, Hudson T and Enneking WF: The correlation between the radiologic staging studies and histopathologic findings in aggressive stage 3 giant cell tumor of bone. Cancer 57: 237-244, 1986.

15. Fletcher CDM, Bridge JA, Hogendoorn P and Mertens F: WHO classification of tumours of soft tissue and bone. Lyon: IARC Press: 239-394, 2013.

16. Livak KJ and Schmittgen TD: Analysis of relative gene expression data using real-time quantitative PCR and the 2(-Delta Delta C(T)) method. Methods 25: 402-408, 2001.

17. Sarsilmaz A, Argin M, Sezak M, Altay C and Erdogan N: Primary osteosarcoma arising from subcutaneous tissue: 5-year follow-up. Clin Imaging 36: 402-405, 2012.

18. Mavrogenis AF, Rossi G, Palmerini E, Errani C, Rimondi E, Ruggieri P, Soucacos PN and Papagelopoulos PJ: Palliative treatments for advanced osteosarcoma. J BUON 17: 436-445, 2012.

19. Shang Y, Li Z, Li H, Xia H and Lin Z: TIM-3 expression in human osteosarcoma: Correlation with the expression of epithelial-mesenchymal transition-specific biomarkers. Oncol Lett 6: 490-494, 2013.

20. Liu H, Zhi L, Duan N and Su P: Abnormal expression of Tim-3 antigen on peripheral blood $\mathrm{T}$ cells is associated with progressive disease in osteosarcoma patients. FEBS Open Bio 6: 807-815, 2016.

21. Piao YR, Jin ZH, Yuan KC and Jin XS: Analysis of Tim-3 as a therapeutic target in prostate cancer. Tumour Biol 35: 11409-11414, 2014.

This work is licensed under a Creative Commons Attribution-NonCommercial-NoDerivatives 4.0 International (CC BY-NC-ND 4.0) License. 